\title{
Urban assets and urban sustainability: challenges, design and management
}

\author{
J. Eyles \\ School of Geography and Earth Sciences and Institute of Environment \\ and Health, McMaster University, Canada
}

\begin{abstract}
Urban assets are key resources, often seen as part of critical infrastructure. They consist of physical elements (often natural or historic) in the city and are linked to quality of life. Innovative people and businesses are also crucial urban assets, necessary to ensure a sustainable urban future. This paper examines the importance of place-making (utilizing such assets) for such a future. It lays out the challenges (e.g., sprawl, brownfield sites, dereliction) facing many cities and the design elements and institutional mechanisms (e.g., local character, density, mixed uses, investment, leadership) to enhance place-making and branding for urban development, growth or revitalization. The paper illustrates the use and enhancement of urban assets for a sustainable economic and environmental future with brief case studies, emphasizing finally the case of an industrial city Hamilton, Ontario.

Keywords: urban assets, design, urban problems, sustainability, institutional mechanisms.
\end{abstract}

\section{Introduction}

In recent years, there has been growing and intense interest concerning critical infrastructure and urban assets. Critical infrastructure has come to the fore largely because of security issues and the need to protect important assets. Canada [1], the European Union [2] and the United States [3, 4] have identified such infrastructure and key assets, largely in terms of physical resources such as telecommunications, power systems, banking and finance, transportation, water supply systems, emergency services (including health care), food systems, commerce and continuity of government. But consideration of these matters, 
particularly in the United States, has added 'key assets' to infrastructure. Key assets include national monuments, symbols and icons representing heritage, culture, values and political power as well as prominent commercial centres, office buildings and sports stadiums where many people regularly come together [3].

While security issues have helped highlight and remind us of the importance of key elements of the urban fabric, the importance of and characteristics of this fabric as well as the innovativeness and productivity of city dwellers have also been identified as key urban assets as cities struggle to compete to keep and attract residents and investments and jobs. For example, Boddy [5] notes the strong connection between economic development and social cohesion/polarization in modern cities [5]. What Florida [6] identifies as important as an urban asset - the existence and vitality of a creative class - may result in negative social consequences: the production of many low-paying service jobs [6]. While the idea of the creative class emphasizing tolerance, talent, creativity, technological innovation has been criticized (see [7]), there is no doubt that 'people assets' are vital to urban well-being. But this well-being while desirable is often difficult to achieve and sustain. In fact, this well-being is based on a complex mix of factors, consisting of the existing economic base (the legacy of location, industry mix etc.) tangible assets (e.g., communications, cityscape, talent), intangible assets (image, culture, engagement in local civic society) and organizational assets (e.g., structure and capacity of local institutions, leadership) (see [8]). In this paper, we emphasize the importance of physical assets for the development and maintenance of urban well-being, seeing these as key for security as well as quality of life.

\section{Place-making and urban assets}

Urban assets or the urban fabric in general do not exist in a social or psychological vacuum. The urban fabric will be valued if it is meaningful to residents, workers and visitors for their security and quality of life. Thirty years ago, Relph [9] argued that places are profound centres of human existence, dramatizing the aspirations, needs and functional rhythms of personal and group life [see also 10]. So place is much more than urban form. It is the text and context for everyday life [11], but one dependent on the ideas and codes of residents (insiders) as well as visitors and the wider social norms and representations of its containing culture [see 12]. In referring to built forms, Lawrence and Low [13, p.466] state "as symbolic, sites condense powerful meanings and values; they comprise key elements in a system of communication used to articulate social relations" [13]. Thus as Knox [14, p.1] argues vital to good urban design is "the capacity of the built environment to foster a positive sense of place in the ordinary places that provide the settings for people's daily lives" [14]. In many respects, this is a return to the plea for liveable cities, which contribute to the physical, social and mental well-being and the personal development of their inhabitants [see 15] and in which the conditions for placemaking are identified. In fact, Warner and Negrete [16] note the social, 
institutional and regulatory capacities required to ensure urban development is liveable and sustainable. We will return to the theme of sustainability later but now move to consider the design elements of place-making.

\section{Urban challenges, design and place-making}

If the urban fabric is vital for a secure, high quality way of life, what challenges have been identified as making place-making for liveability and sustainability more difficult? In North America especially, most cities continue to be dominated by the decentralization of population and employment. The resulting sprawl, long journeys to work, homogenized architecture and sites, abandoned land and the diffused nature of critical infrastructure has led to several policy initiatives. Three important discussions are highlighted as they bring together the importance of physical assets, innovation in technology and governance and sustainability and liveability. The first identifies the major challenges for cities [17]. Six are noted: the unchecked expansion of urban areas leading to inefficient and insecure resource use and the degradation of inner cities, especially through the construction of single-use developments reliant on private car use; old industrial sites often embedded in residential areas being abandoned and left derelict as jobs move to the suburbs; the existence of brownfield sites often contaminated and dangerous and expensive to clear hampering revitalization efforts in older denser parts of cities; construction itself is often noisy and wasteful resulting in inefficient resource use which may be remedied by sustainable, often green, techniques; the failure to maintain existing or create new green space being detrimental to health and quality of life as well as good design practice; and deprived areas and distressed neighbourhoods being a symptom and cause of downtown and inner city decline and their regeneration being key to safe secure living.

The presence of these characteristics may make such (parts of) cities unattractive to investment and in-migrants. While their mitigation requires sustained regulator and institutional action with committed leadership and resources, design plays a key role in maintaining and enhancing urban assets the fabric of place-making. The New Zealand Ministry of Environment [18] has initiated an investigation of the value of urban design elements. They note that good urban design not only demonstrates excellence in architecture and development but also produces environmental benefits, responds to local features and needs, is adaptable, forges connection with the past and distributes its benefits widely in the population. Eight elements are noted. First urban design must respect and support local character. This can reinforce a sense of identity, encourage conservation, help in image building, add economic value to an area and help attract high-value businesses and workers. Secondly, connectivity ensures that access within the area and between it and others is facilitated. Such access can assist local economic activity, enhance safety and security, reduce vehicular traffic and enhance land-values. Thirdly, density can reduce economic and infrastructure costs, help concentrate knowledge and innovative activity usually at the city's core, reduce all emissions to the environment, promote 
social connectivity and conserve green space. Fourthly, encouraging mixed uses in or close to neighbourhoods can offer convenience and choice, encourage local business, increase personal safety through surveillance and enhance social equity. Fifthly, adaptability can increase the capacity of buildings, spaces and neighbourhoods. It will increase the diversity of uses and users in a space, extend the life of sites and encourage conservation. Sixthly, a high quality public realm can be created through the creation and maintenance of public structures and spaces. This can improve the use of such spaces, encourage participation in civic affairs, enhance public safety and improve the image of a neighbourhood or city. Seventhly and lastly, important process issues are noted to ensure efficiency, transparency and equity. So user participation in design to enhance a sense of community and local democracy and integrated decisionmaking to ensure complementary urban policies are discussed.

These design characteristics are perhaps commonplace now and underpin many twentieth-century solutions to urban challenges - new urbanism, Smart Growth, Slow Cities. They emphasize continuity and sustainability as well as community-oriented planning and policy-making. They indeed point to the three key dimensions of sustainability - the need to treat the social, the economic and the environmental. That complexity may in itself stymie many efforts to improve the urban fabric or protect urban assets for the security and quality of life of citizens. Indeed without institutional and organizational capacities and mechanisms they are likely to remain merely good ideas. We thus turn to our third strand. Brophy and Vey [19] provide a guide to reform the land development process to help realize urban assets for place-making. They outline a ten step process which begins by knowing the city (e.g., Neighbourhood Knowledge, Los Angeles) and developing a city-wide as opposed to piecemeal approach (e.g., Philadelphia's five year neighbourhood transformation initiative). Neighbourhood plans must be implemented in partnership with local stakeholders to be successful. But they also require effective local government with a clear political and administrative strategy (see Dan Diego's vacant properties program). This requires a legal framework for enabling good design and development, usually in partnership with state or provincial bodies. Furthermore, the city may need to aid such development and design by land assembly, carrying out environmental remediation and establishing new building codes (e.g., New Jersey's smart codes). Cities may also need to assist financially in some developments, especially with respect to brownfields or depressed neighbourhoods or downtown areas. In all this, cities can build on natural and historic assets such as water fronts, parks and heritage districts. There must further be a recognition that some design and development decisions have negative consequences and may require further strategies. So renewing the urban fabric may reduce the number of homes for long-time residents and their families. So an affordable housing strategy is required. And finally, to succeed cities need not only resources but also leadership, partnerships but also recognition of capacity and its limitations.

Together these three reports - similar in themselves - provide guidance on the challenges to the urban fabric, the role of design in maintaining and enhancing 
assets in that fabric and the organizational requirements for such design to be implemented and sustained. Using urban assets to sustain urban place-making and liveability is not easy. It is a complex task. We will now finally turn to some examples of using and re-using urban assets. Let us note that one solution does not/cannot apply to all cities because of their very different sizes, histories, cultures and contexts.

\section{Case-studies in urban sustainability}

Let us recall that a main purpose of using (and re-using) urban assets is for their contribution to security and quality of life. Good urban assets are key with innovative people for urban development, growth and revitalization. A repository of good assets can be enhanced by design elements to improve the image or brand of the city for residents and outsiders. Promoting distinctive brands is now commonplace (see [20]) as these images have longevity and many cities have tried to shape them through design utilizing the assets that they have available, adding to or refurbishing the urban fabric. These images once formed are difficult to change and if negative may make it difficult to attract new residents and/or economic investments. Older industrial cities find it particularly difficult to remake themselves but many emphasize urban assets to promote distinctive brands but must achieve a balance between maintaining local distinctiveness for residents and providing a range of safe, pleasant attraction for visitors. Amsterdam, for example, has aimed for redevelopment for residents as well as visitors (see [21]).

With the dominance of consumption and lifestyle options (see [22]) in modern cities, it is not surprising that many cities have emphasized tourism as a revitalization/growth strategy. This is often based on creating new entertainment or sports complexes often close to historic areas or which use a natural feature. For example Chattanooga realized in the 1980s that it had turned its back on its major asset - the Tennessee River - in its attempts to free itself from a situation of high pollution levels, declining economy and population and few prospects. With citizen buy-in and leadership from the non-profit River Valley Company initial projects began, although at above market-rate risk. After the success of its initial plans which focused on a large aquarium, children's museum, speciality retail, new housing, improved streetscape and above all a river walk, the city went further. It has built new stadia, launched affordable housing programs, constructed an entertainment centre and refurbished abandoned industrial sites for housing (see [23]). Chattanooga has successfully built on its assets and through good design and institutional mechanisms has reached a new urban sustainability. A similar success story may be found in Albuquerue after several failures in which convention centres and plazas, improved retail and streetscape did not seem to work. Investment capital and strong leadership led to success in the post-2000 period.

But the situation of Albuquerue in the 1990s reflects many cities which have urban assets but fail to capitalize on them and make themselves sustainable. Indeed as Teaford [24] has argued this is not surprising given the economic and 
political forces that led to the decline in attractiveness of urban assets in older cities and their downtowns and the relative attractiveness of investment and residence in the new suburbs [24]. We have described the design elements that are meant to turn around this situation, many being based on the density and scale arguments of such writers as Jacobs and Kunstler. The ingredients are not hard to specify: revitalizing neighbourhoods and bringing in new residents to increase an area's spending power, emphasizing historic and natural assets and green, sustainable development more generally and ensuring sufficient leadership, investment and time commitment for assets to be refurbished or recreated. Easy to say, hard to do.

For most old industrial areas, it is unfair and unhelpful to point to major tourist destinations as examples. They do however point up the fact that even strongly defined and articulated urban assets and liveability cannot be left or decline will set in. New York City has again become a place the assets of which with investment and emphasis on security and image has become desirable, despite economic and political crises through the 1960s-1980s. The design refurbishment of Times Square demonstrates the importance of government leadership and resources, streetscaping and law enforcement, and private investment to build on existing entertainment assets [25]. Entertainment complexes are not always successful. Detroit's lack of success shows the importance of existing assets and governance and social context (see [26]). But the rigorous governance and planning regime of Barcelona has resulted in what many regard as a place with significant cultural, historical and natural assets in its centre (see [27]). Smaller, less well-known places can also utilize such assets as Timothy and Boyd [28] show for Burslem, an older pottery industry town with an architectural and industrial heritage and for Belfast, which has used its old industrial waterfront for recreation and new residences [28].

Many of these ingredients are present in smaller industrial cities but rebuilding on existing assets has not worked. Akron (Ohio) remains mired in its decline. So to some extent does Hamilton, Ontario, an industrial city of about half a million people. With still functioning and efficient steel plants and other heavy industry, Hamilton is also a centre of education and health care promotion. Hamilton, in its Vision 2020 statement, adopted in 1992, chosen a sustainable, green development approach which could emphasize its position on Lake Ontario and the Niagara escarpment. The city is surrounded by and contains many green spaces and this approach seemed ideal. The city aims therefore to maintain environmental integrity as well as social quality as well as economic prosperity (see $[29,30])$ this being a common approach internationally (see, [31, 32]). Utilizing an integrated planning and citizen participation approach, Vision 2020 identifies 14 theme areas including local economy, natural areas, waste reduction, heritage preservation, safe and security, and community well-being with targets and indicators. At the same time, the city has a downtown in serious decline and heritage buildings in various states of repair. The city has a neighbourhood planning strategy and invests to assist developers establish new residences downtown. But it does not score highly in terms of an innovative presence [33]. Some thirty years ago, it built a convention centre, shopping mall, 
and entertainment facilities in its downtown. It has recently begun to quieten its core streets by reintroducing two-way traffic and more on-street parking. But a malaise still hangs over Hamilton. Why? While it is difficult to see one factor involved, several elements have conspired against it. Political and geographic context has not helped. Service downloading has given the city a massive welfare payment burden and its proximity to Toronto means that minor assets are difficult to play up to attract visitors. But its affordability for new residents and businesses seem to make it attractive. Perhaps in part, its lack of focus on a refurbishment strategy (not staying the course), its developer-friendly attitude (especially for greenfield site development) and its divisive political culture can be implicated. But it has natural assets (and some heritage ones) that in a coherent strategy could be used for a sustainable future. But that would mean adhering to the principles of sustainability, e.g., containing growth, integrating economy with environment and emphasizing sustainable construction (see [34]), which are not enhanced by the city's current political practice.

\section{Concluding remarks}

Hamilton's case demonstrates that it is not simply a matter of identifying the right ingredients to (re-) design and manage urban assets for a sustainable urban future. Careful citizen involvement may be required to establish a direction. Furthermore without tangible assets (green space, architectural heritage) and the legislative and financial context to protect or enhance such assets it is also difficult to 'manufacture' the intangible asset of image or brand. Yet residents are vital as they make the city a meaningful place. They, along with investment and leadership, are necessary to create a climate to attract new residents, especially to core or downtown areas. Thus a strategic plan is necessary that emphasizes urban assets such as character, housing, retail, infrastructure, employment and culture. Planning tools and mechanisms exist to do that improvement areas, enterprise zones, empowerment zones. Turning the intention to regenerate using urban assets to the critical mass of successful revitalization or growth is not easy. The fact that so many places try demonstrates its importance. Finding a city's niche and identifying its worthwhile assets are vital but without good planning, purposeful design and construction and public-private-citizen partnerships (and preventing developments that do not fit the strategic plan) a sustainable future will remain elusive.

\section{References}

[1] Canada, About critical infrastructure, Public Safety and Emergency Preparedness Canada, www.spepc.gc.ca/prg/em/nciap/about-eng.asp, (accessed November 28, 2006) 2005.

[2] European Union, EU critical infrastructure protection, Report 13882/05, EU Presidency, Brussels, 2005. 
[3] CRS (Congressional Research Service), Critical infrastructure and key assets, Library of Congress, Washington, 2004.

[4] CRS, Critical infrastructure: the national asset database, Library of Congress, Washington, 2006.

[5] Boddy, M., Competitiveness and the social fabric, in I. Begg (ed.) Urban competitiveness, Policy Press, Bristol, 2002.

[6] Florida, R., The rise of the creative class, Washington Monthly, www.washingtonmonthly.com/features/2001/0205.florida.html (Accessed November 28, 2006), 2002.

[7] Peck, J., Struggling with the creative class. Internat. J. Urb. Reg. Research 29, 740-770.

[8] Docherty, I. et al., Exploring the potential benefits of city collaboration, University of Glasgow, Urban Change and Policy Research Group, Discussion Paper 8, 2003.

[9] Relph, E., Place and placelessness, Pion, London, 1976.

[10] Tuan, Y.-F., Space and place, Arnold, London, 1977.

[11] Aravot, I., Back to phenomenological placemaking. Journal of Urban Design 7, pp. 201-212, 2002.

[12] Lomitz, L. \& Diaz, R., Cultural grammar and bureaucratic rationalization in Latin American cities, in R. Morse \& J. Hardoy (eds.) Rethinking the Latin American City, Woodrow Wilson Center, Washington, 1992.

[13] Lawrence, D. \& Low, S., The built environment and spatial form. Annual Review of Anthropology 19, 453-505, 1990.

[14] Knox, P., Creating ordinary places. Journal of Urban Design 10, 1-11, 2005.

[15] Timmer, V. \& Seymoar, N., The liveable city, Vancouver Working Group Discussion Paper, International Centre for Sustainable Cities, Vancouver, 2005.

[16] Warner, K. \& Negrete, J., The urban growth machine goes south: conditions and capacities for more sustainable place-making. Local Environment 10, 571-593, 2005.

[17] European Commission, Building the future, EU Research for Sustainable Urban Development and land Use, EU, Luxembourg, 2004.

[18] New Zealand Ministry of Environment, The value of urban design, http:/www.mfe.gov.nz/publications/urban/value-design-full-report-jun05/ html, (Accessed September 22, 2006) 2005.

[19] Brophy, P. \& Vey, J., Seizing city assets, Brookings Institution, Center on Urban and Metropolitan Policy, Washington, 2002.

[20] Bramwell, B \& Rawding, L., Tourism marketing images of industrial cities. Annals of Tourism Research 23, 201-221, 1996.

[21] Terhorst, P. et al., Amsterdam: it's all in the mix, in L. Hoffman et al. (eds.) Cities and visitors, Blackwell, Malden, 2003.

[22] Zukin, S., Landscapes of power, University California Press, Berkeley, 1991.

[23] Leinberger, C., Turning around downtown, Brookings Institution, Metropolitan Policy Program, Washington, 2005. 
[24] Teaford J., The rough road to renaissance, Johns Hopkins Press, Baltimore, 1990.

[25] Sagalyn, L., Times square roulette, MIT Press, Cambridge, 2001.

[26] McCarthy, J., Entertainment-led regeneration: the case of Detroit. Cities 19, 105-11.

[27] Garcia, M. \& Claver, N., Barcelona: governing coalitions, visitors and the changing city centre, in L. Hoffman et al. (eds.) Cities and visitors, Blackwell, Malden, 2003.

[28] Timothy, D. \& Boyd, S., Heritage tourism, Prentice Hall, Harlow, 2003.

[29] Bekkering, M. \& Eyles, J., Making a region sustainable in M. Hoff (ed.) Sustainable community development, Lewis, Boca Raton, 1998.

[30] Hamilton Vision 2020, www.myhamlton.ca/myhamilton/Cityand Government/ProjectInitiatives/v2020 (Accessed November 28, 2006) 2006.

[31] ICLEI (International Centre for Local Environmental Initiatives), Local government for sustainability, www.iclei.org/ (accessed November 29, 2006) 2006.

[32] Sustainlane, Sustainlane's 2006 US city sustainability ranking, www.sustainlane.us/overview.jsp (Accessed November 27, 2006) 2006.

[33] CCS (Centre for Community Study), Hamilton and the creative class, CCS, Hamilton, 2004.

[34] Gaffikin, F. \& Morrissey, M., City visions, Pluto Press, London, 1999. 